\title{
Fractal geometry and design of modern structures
}

Irina Mayatskaya*, Irina Kashina, Natalia Gerlein, and Batyr Yazyev

Don State Technical University, 344022, Rostov-on-Don, Russia

\begin{abstract}
One of the main directions in the application of mathematical methods in construction - is to create the complex objects using simple algorithms of fractal geometry with the use of computer technology. The use of fractal geometry methods to describe real systems, in particular, in the development of the architectural appearance of the city and the design of modern structures of the most amazing shape, will allow solving the problems of research and forecasting the urban environments development.
\end{abstract}

\section{Introduction}

Fractal geometry studies the properties of objects that have fragmentation, broken lines, fuzzy boundaries and fractional dimensions [1-4]. The term "fractal" was introduced in 1975 by Benoit Mandelbrot. Typically, fractals have the following classification: geometric, algebraic, stochastic and systems of iterative functions (Fig. 1), for which there is the following classification: IFS (Iterated Function Systems) systems and L-systems [5, 6]. The main idea of the L-system is a way to obtain the complex objects by replacing the parts of the initial element according to certain rules. But there are other properties of fractals as well. These are dissymmetry and scaling. Dissymmetry is the unity of symmetry and asymmetry, and scaling is a changing similarity.
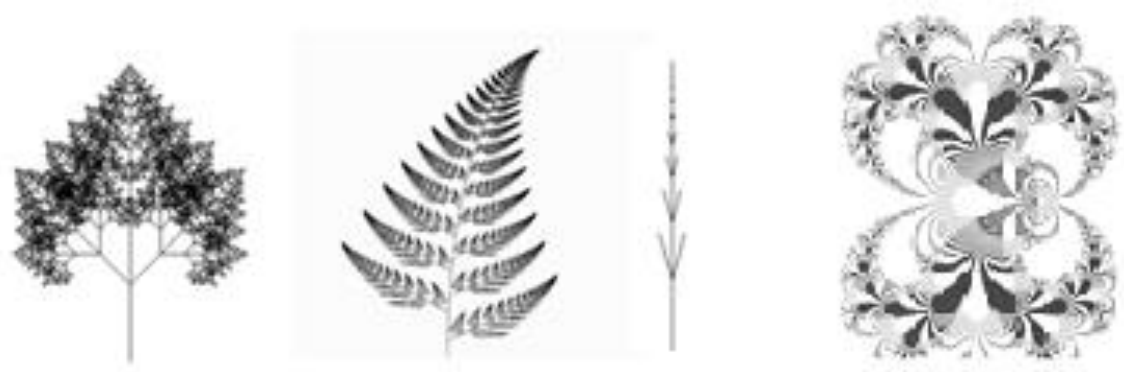

Fig. 1. Fractal as Iterated Function Systems with different parameters.

Fractality means variability, almost the same at all levels of the structure under consideration [1-4]. Self-similarity is a process in which a part of an object changes in a certain way in accordance with the fractional dimension, i.e. an increase or decrease, is superimposed on the entire object, creating a completely new structure. In addition to the

${ }^{*}$ Corresponding author: irina.mayatskaya@mail.ru 
self-similarity property, fractal geometry has other properties: dissymmetry and scaling. If the first concept means the interpenetration of symmetry and asymmetry, then the second is similarity with sliding. In this theory, Mandelbrot also considers the dynamic development of systems. For his discoveries in fractal geometry, he was awarded the Wolf Prize in 1993. Figures 2 - 5 show the examples of a wide variety of fractals.

Fractals, constantly changing, are able to create ever new, most diverse forms from a predetermined initial structure. This is the advantage of the fractal method. Fractals are the models of dynamic systems capable of development and change, and they contribute to the creation of a whole from fragments, where the next step is based on the development of the previous one. This makes the object unique, completely different from the initial structure.
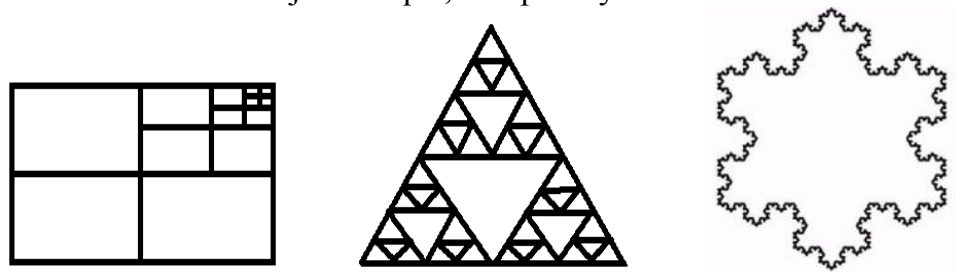

Fig. 2. Geometric fractals. Number of repetitions -4 .
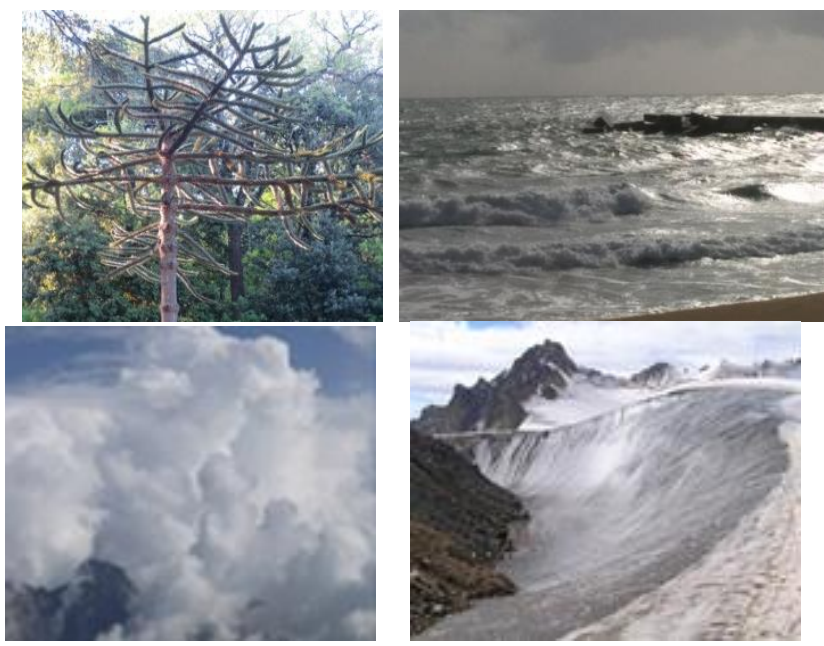

Fig. 3. Natural objects with a fractal surface (plant, sea, clouds and mountains).
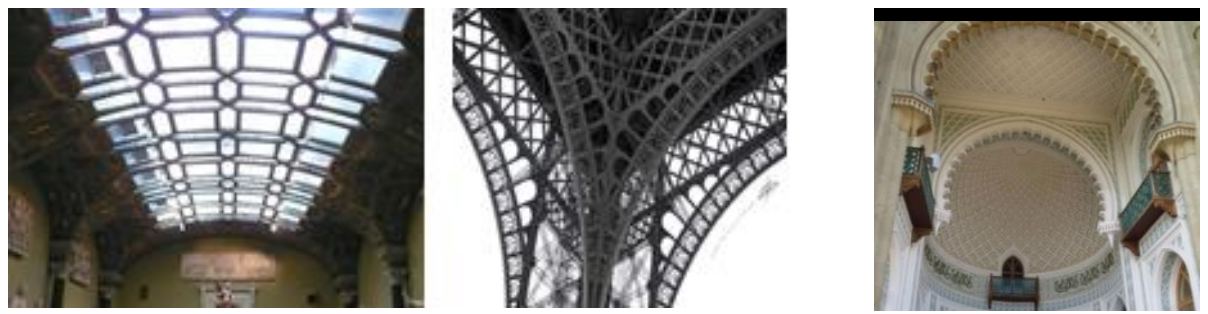

Fig. 4. Architectural fractal elements with hard similarity. 


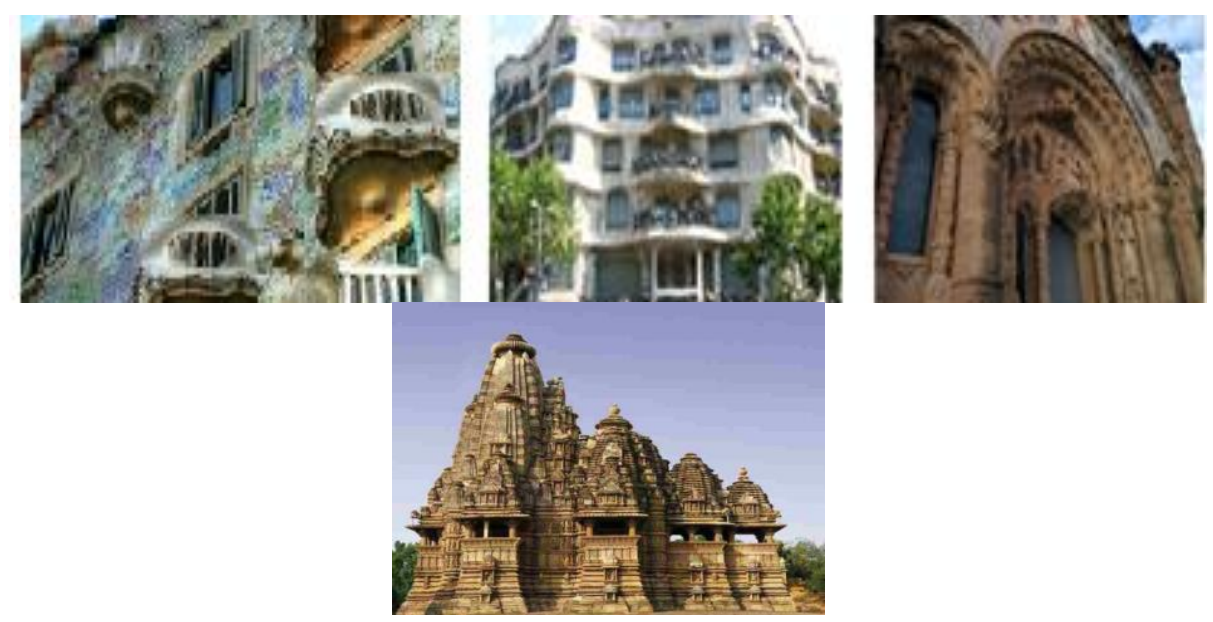

Fig. 5. Buildings with fractal properties.

To set a fractal structure means to set the principle of constructing a form and structure, taking into account its changes and dynamics. These objects of shaping are based on the principle of unity in diversity. Two directions can be used to construct fractals. The first is repeating the same part without changing. The second is the creation of a whole from parts, where the next step in modeling an object is based on the development and shaping of the previous one, but at a different development level. It is the second direction in the development of dynamical systems using the methods of fractal geometry that is interesting in the frames of structures design.

It is necessary to conduct further research related to fractal analysis. In fractal architecture, the following principles are applied: self-similarity; dynamism, ability to develop; irregularity; recursiveness; fractionality. By using the principles of fractal, it is possible to create an amazing form of architectural objects, to study the architectural composition of buildings, to design buildings with a rational organization of space and taking into account the environmental requirements of environmental protection.

We can say that the fractal approach is an effective way to analyze the already built structures, as well as a way to design such architectural objects that can enrich the achievements of world architecture.

\section{Fractal approach as a way of designing architectural forms}

The fractal approach is a way of analyzing and designing the architectural forms that would significantly enrich modern architecture [7 - 10]. Fig. 6 shows the architectural appearance of a modern city (Fig. 6).

Fractal architecture can be divided into two types: artificially created, which is intuitive and conscious and naturally formed. The principles of fractal architecture are applied to the construction of both individual objects and in urban space organization [7-14].

Application of repetitive self-similar forms is widespread in designing a wide variety of structures. In the past, the architectural elements during construction were the same. But the architects were able to create amazing structures intuitively using the fractal architecture principles $[8,10]$. This made the objects completely unique, the architects knew how to organize and make beautiful the interior space and the facade, which made these structures unique (Fig. 7). 

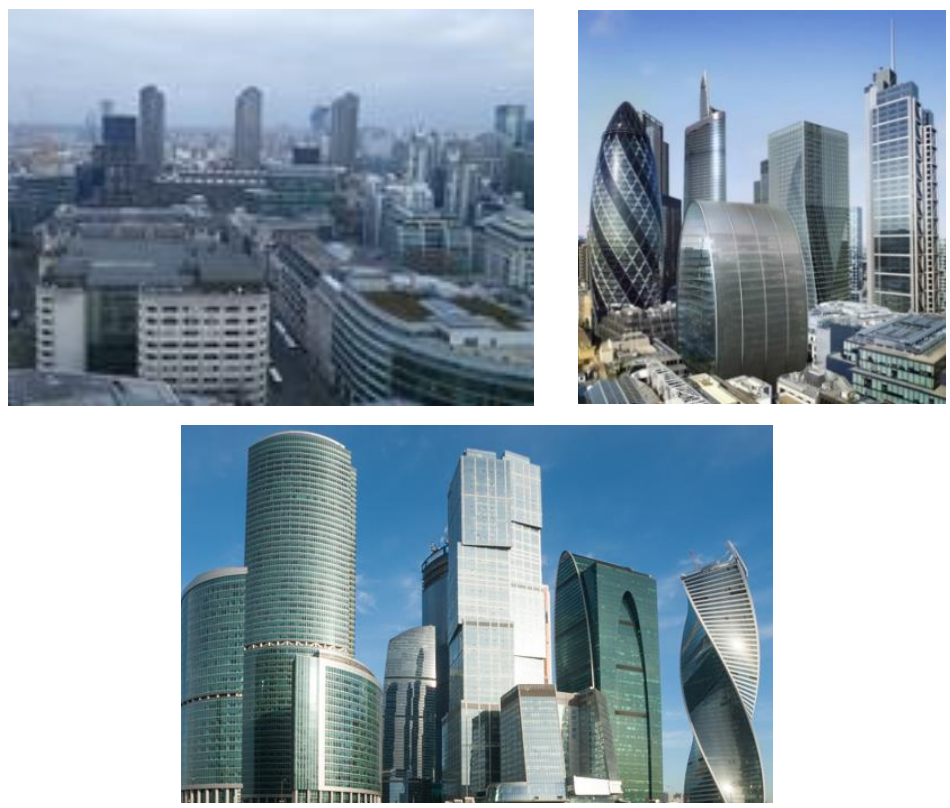

Fig. 6. A modern city view
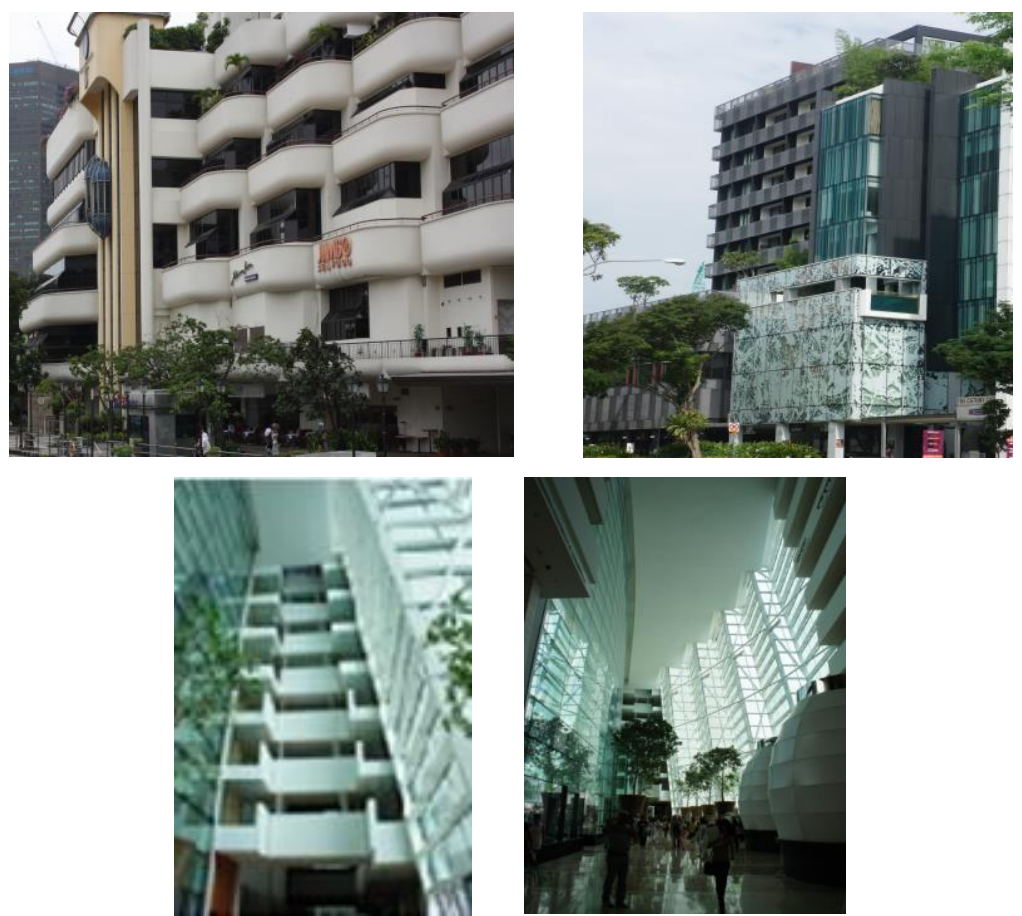

Fig. 7. Facade and interior space in a modern city.

But computer technology development has made it possible to design and implement the most unusual projects. And the fractal approach as a research method, a way of designing and modeling architectural forms helps in creating amazing and beautiful structures and complexes of buildings [15-20]. Intuitive fractality is presented in many 
structures of world architecture in the similarity of lines, shapes and surfaces of elements of these structures (Fig. 8, 9). The names of such architects as Antoni Gaudi, Zaha Hadid, Jem Utzon, Gottlieb Eltel Saarinen, Renzo Piano, Gottfried Böhm, Frank Owen Gehry should be recalled here.
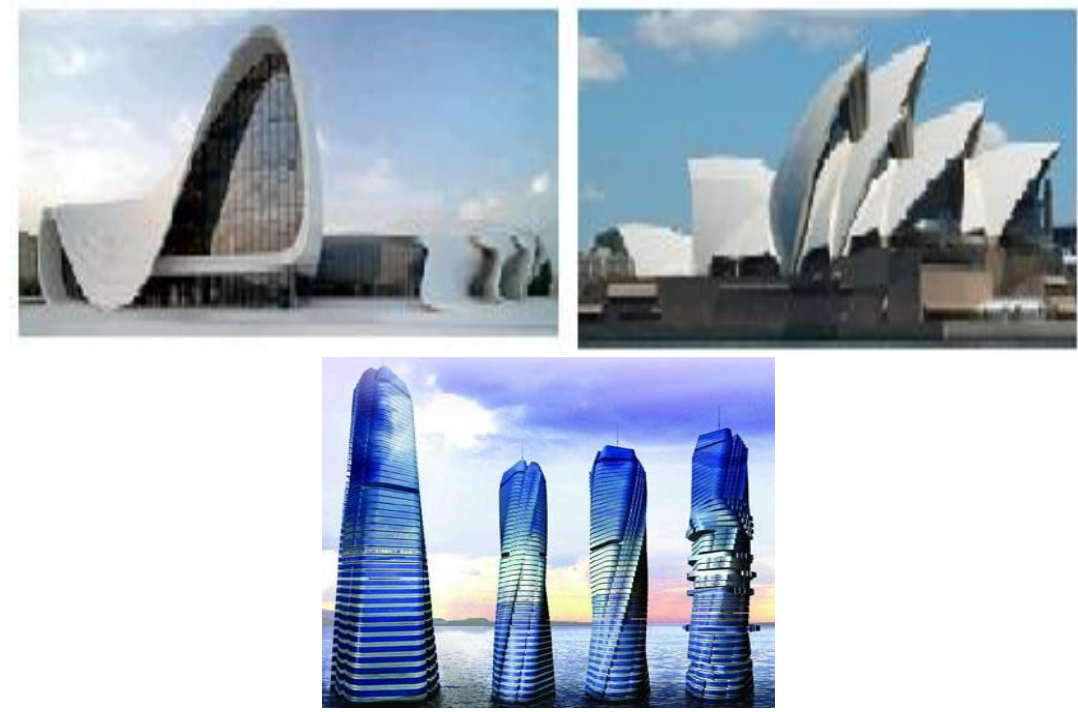

Fig. 8. Cultural Center named after Heydar Aliyev in Baku (architect Zaha Hadid) and Opera House, Sydney, Australia (architect Jem Utzon), Revolving skyscraper project (architect David Fisher)
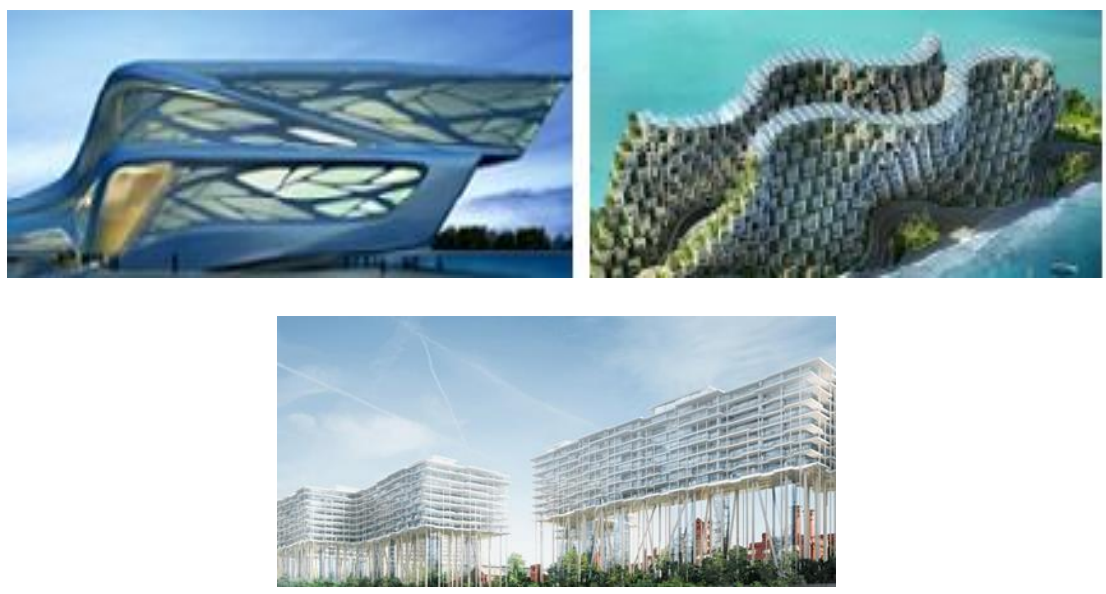

Fig. 9. Cultural Center, Abu Dhabi, United Arab Emirates (architect Zaha Hadid) and Project The «Coral Reef» (architect Vincent Callebaut), housing complex «Badayevsky» (architectural bureau "Herzog \& de Meuron")

In such different shaped buildings like the skyscrapers tower "Evolution", "Moscow", "Shanghai Tower» and Daniel Libeskind house, two properties of fractal geometry can be traced: dissymmetry and scaling (Fig. 10).

Dissymmetry is a combination of symmetry and asymmetry, and scaling is a changing likeness or resemblance with sliding. The blocks of the Shanghai tower have a similar shape in combination with a facade twisted along the building height. In the house of Daniel Libeskind, the method of forming with sliding was also used, but already along the facade plane. 

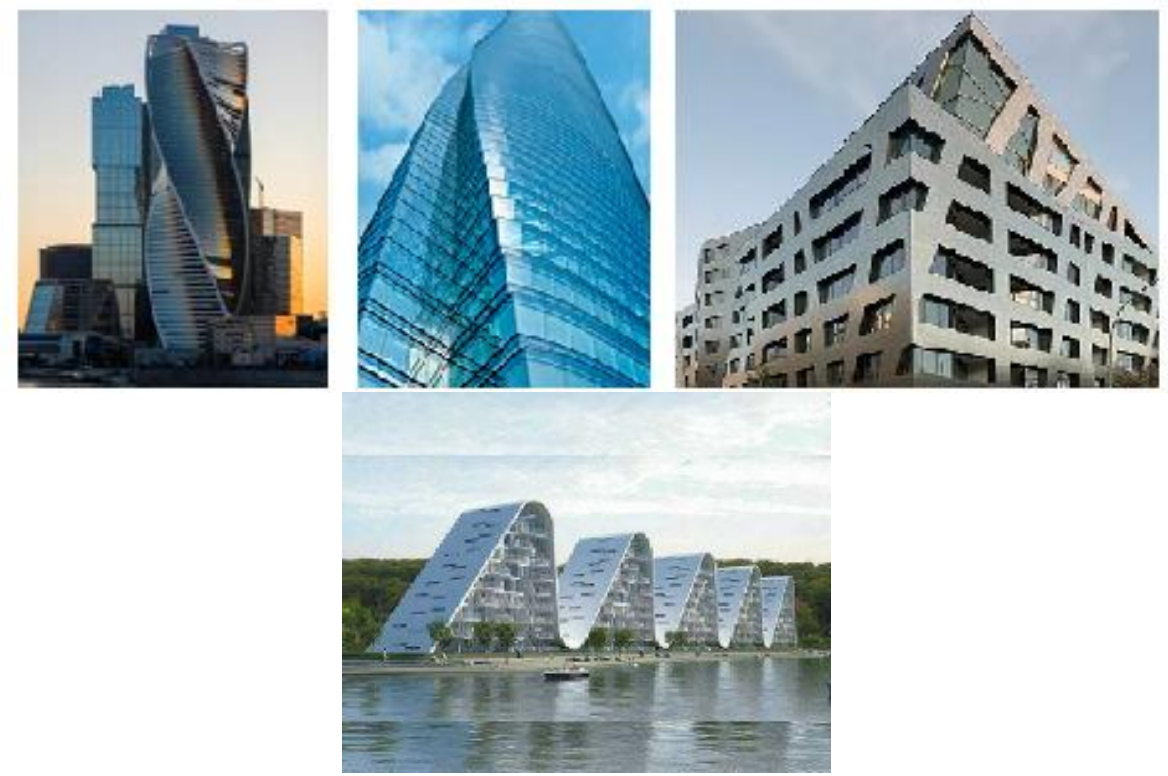

Fig. 10. Tower "Evolution", Moscow-City; skyscraper «Shanghai tower», Shanghai; House of Daniel Libeskind, Berlin and residential complex Vejle, Denmark

Fractal algorithms are usually used in architecture according to the rules for constructing the structure of an object using a limited number of repetitions, changing rules, changing the rigid similarity of structure elements. With the use of computer modeling methods, the possibilities of designers are expanded to create projects using a wide variety of fractals.

\section{Fractal geometry and urban development}

Based on the use of the most modern software systems, it is possible to create architectural forms with a fractal structure. The use of fractal geometry methods in the design process of buildings that are unique in shape allows to form a harmonious combination of the irrational and rational, making the city's appearance unique.

City is a fractal space consisting of buildings, complexes of buildings, transport networks and natural features creating a comfortable environment in which people live. [20]. Architects noticed that a person is stressed if he is surrounded by concrete buildings in the form of rectangular spatial objects. And he starts feeling better surrounded by nature or historical buildings, in the construction of which architects intuitively used a variety of fractal and bionic elements.

A city is a spatial and conceptual multifractal of a stochastic type. Thus, the concentric building of the historical center of Moscow or the linear-square layout of New York is a spatial fractal that has a repeating construction algorithm. Of course, there are random changes in this space organization but they generally do not affect the overall structure of the city. And other cities also have their own building features.

It is necessary to carry out the comprehensive studies and taking into account the fractality of the city space itself for the urban environment harmonious development [2124]. Fractal analysis in contemporary research is widely used for the study of dynamical systems. In the world, the research was carried out by the following scientists: M. Betty, P. 
Loughley, as well as Le Corbusier, F.L. Wright, Zaha Hadid and P. Frankhoser, developing a whole architectural direction - "fractal urbanism".

The plan for the urban environment development should be drawn up on the basis of a forecast using the methods of mathematical modeling for dynamic systems, taking into account the structure complexity, the introduction of the most diverse and sometimes unexpected development vectors.

It is necessary to understand that at the moment the mathematical methods of fractal geometry cannot simulate a real dynamic system based on taking into account all the specific parameters of the urban environment, but can only make a forecast of the development of the city system. But mathematical methods and computer technologies are being developed quite intensively, and it will be quite possible to model the city development in the future.

\section{Conclusion}

Modern architects and designers are looking for graphic fractal images, architectural forms in $2 \mathrm{D}$ and $3 \mathrm{D}$ formats, and involve the computer modeling methods in their research. It is necessary to note that the unique elements of the structure are not the static objects, but a trail of movement, bending, fractures of surfaces, fuzzy boundaries, soft forms that imitate the lines of living nature. Fractal algorithms allow compression, rotation, nonlinear transformations of the original shape.

In order for our world to become beautiful and harmonious, it is necessary to apply the methods of computer modeling more widely and introduce digital technologies into design practice to create the complexes of unique structures and a comfortable living environment for the population.

\section{References}

1. H.-O. Peitgen, D. Saupe, The Science of Fractals Images (Publishing house Springer, New York, 2012).

2. D.P. Feldman, Chaos and Fractals: An Elementary Introduction (Publishing house Oxford University Press, Oxford, 2012).

3. D.P. Feldman, Chaos and Dynamical Systems (Publishing house Princeton University Press, Princeton, 2019).

4. H.-O.Peitgen, H. Jurgens, D. Saupe, Chaos and Fractals. New Frontiers of Science, (Publishing house Springer Science\&Business Media, New York, 2004).

5. I.A. Mayatskaya, T.A. Medvedeva, Mathematical modeling of plant objects using elements of fractal geometry (Proceedings of the VII International Seminar, SAUandOI 2016, 6-12 October 2016, Divnomorskoe, Russia, 2017) pp. 44-49.

6. T.A. Medvedeva, I.A. Mayatskaya, V.Yu. Motovilina, K.A. Chugunny, Mathematical modeling of plant material using systems of Lindermayer, (Proceedings of the VIII International Seminar, SAUandOI 2017, 8-13 October 2017, Divnomorskoe, Russia, 2018).

7. I.A. Mayatskaya, S.B. Yazyeva, A.P. Lapina, V.V. Davydova, IOP Conference Series: Materials Science and Engineering 913 (2), 022070 (2020).

8. S.B. Yazyeva, I.A. Mayatskaya, I.V. Kashina, A.N. Nesterova, IOP Conference Series: Materials Science and Engineering 698 (3), 033046 (2019). 
9. I.A. Mayatskaya, S.B. Yazyeva, M.A. Kolotienko, B.M. Yazyev, IOP Conference Series: Materials Science and Engineering 698 (2), 022083 (2019).

10. B.M. Yazyev, I.A. Mayatskaya, S.B. Yazyeva, S.B. Yazyev, IOP Conference Series: Materials Science and Engineering 698 (2), 022087 (2019).

11. I.A. Mayatskaya, S.B. Yazyeva, B.M. Yazyev, P.B. Kulinich, MATEC Web of Conferences 106, 01031 (2017).

12. I.A. Mayatskaya, V.D. Eremin, E3S Web of Conferences 110, 01042 (2019).

13. I.A. Mayatskaya, S.B. Yazyeva, N.I. Zakieva, A.P. Lapina, MSF 931, 754-758 (2018).

14. I.A. Mayatskaya, S.B. Yazyeva, B.M. Yazyev, Construction and industrial safety 12 (64), 29-32 (2018).

15. L. Sherr, A. Dent, Material innovation: architecture (Publishing house Thames \& Hudson Ltd, London, 2014).

16. Z. Hadid, A. Betsky, Zaha Hadid: The complete buildings and projects (Publishing house Thames \& Hudson Ltd, London, 1998).

17. Z. Hadid, A. Betsky, Zaha Hadid (Publishing house Skira Rizzoli Publications, New York, 2013).

18. I.A. Mayatskaya, S.B. Yazyeva, B.M. Yazyev, Construction and industrial safety 9 (61), 7-11 (2017).

19. I.A. Mayatskaya, V.D. Eremin, B.E. Turtogtoh, Proceedings of the: Scientific research of the SCO countries: synergy and integration, 116-124 (2019).

20. I.A. Mayatskaya, V.D. Eremin, S.B. Yazyeva, Construction and architecture 7 (1), 9196 (2019).

21. M.V. Shubenkov, Structural patterns of architectural shaping (Publishing house Architecture-C, Moscow, 2006).

22. M. Kushner, The Future of Architecture. 100 most unusual buildings (Publishing house AST, Moscow, 2016).

23. K.V. Kudryashev, Architectural Graphics (Publishing house Architecture-C, Moscow, 2006).

24. P.P. Gnedich, World Architecture (Publishing house Eksmo Press, Moscow, 2012). 